\title{
Characterization of parameters to predict the structural behaviour of geopolymeric mortar plates strengthened with carbon fiber reinforced polymer
}

\author{
PAPPALARDO JR., Alfonso ${ }^{1, a}$ JALALI, Said ${ }^{2, b}$ SILVA, Felipe José $e^{3, c}$ \\ ${ }^{1}$ Universidade Presbiteriana Mackenzie - 01302-907 São Paulo, Brasil \\ 2 Universidade do Minho, Campus de Azurém - 4800-058 Guimarães, Portugal \\ ${ }^{3}$ Instituto Federal de Educação, Ciência e Tecnologia do Rio de Janeiro \\ 26600-100 Rio de Janeiro, Brasil \\ aalfonso@mackenzie.br, bsaid@civil.uminho.pt, ${ }^{\text {'f }}$ elipe.silva@ifrj.edu.br
}

Keywords: geopolymer mortar, carbon fiber fabric, fracture energy, nonlinear analysis, finite element analysis, sustainability and construction materials.

\begin{abstract}
This study includes the identification of parameters for the characterization of the structural behavior of thin plates composed of geopolymer mortars structured with bi-directional carbon fiber mesh. Initially, facade projects, designed by offices in São Paulo using the concepts of sustainable architecture, promoting the use of geopolymeric materials are presented. Then shows the composition of the geopolymer mortar used in this study and the characterization of their mechanical properties. As part of the experimental program, this study evaluates the plate bending behavior and the effect of pull-out test and push-off test of the metallic inserts. It has used the advanced features of ATENA computational mechanics program, which correspond to the state of the art in Finite Element Modeling of reinforced concrete structures, which allow the calibration of the mathematical model based on information from the experimental program. The numerical results showed satisfactory adhesion with the experimental results. It also has emphasized the importance of validation of these results on the determination of loads collapse of structural elements, as is reflected positively in the field of Structural Engineering in the face of increasing advancement of surface modeling programs and technological innovations in according to sustainability criteria for constructions materials.
\end{abstract}

\section{Introduction}

The digital revolution has led to rapid development of various generative modeling tools in the last decade that introduced the concepts of parametric architecture and digital fabrication. The interrelation between architectural design, structural design and manufacturing has been a key to be overcome for the application of these technological innovations point. Hungerburg station's covering (Fig. 1) is a design paradigm of integrated design to manufacturing process. The geometric model was generated from NURBS surfaces (Non Uniform Rational Basis Spline) with isoparametric curves and segmented into smaller panels, with unique size and shape. The panels were manufactured in fiberglass, with information taken directly from the digital model, and fixed in a tubular metallic structure designed in order to support them exactly in their final positions [1]. This new class of generative programs allows users to implement their own algorithms through an open code. This feature extends dramatically the power of creation and generation of these programs. The Figure 2 shows some examples of discrete surfaces used for the geometrical definition of the structural elements supporting the glass skin facade of buildings. 


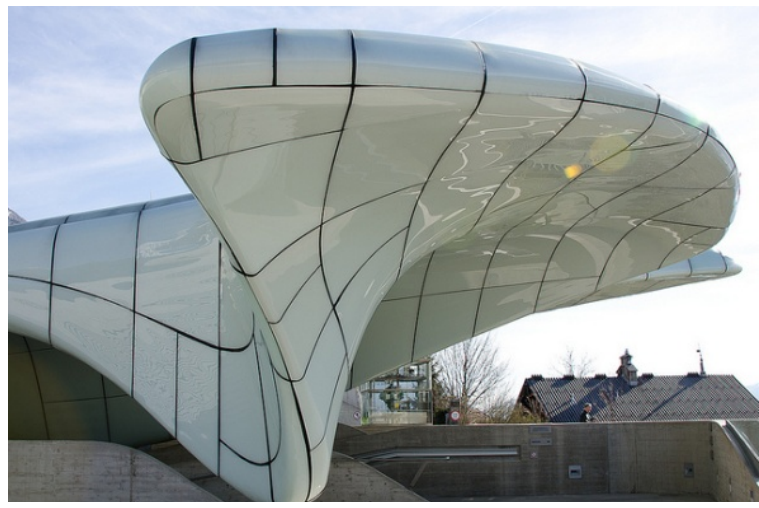

Figure 1: Hungerburg funicular station (Austria)

Project: Zara Hadid Architects Avaliable in: www.flickr.com

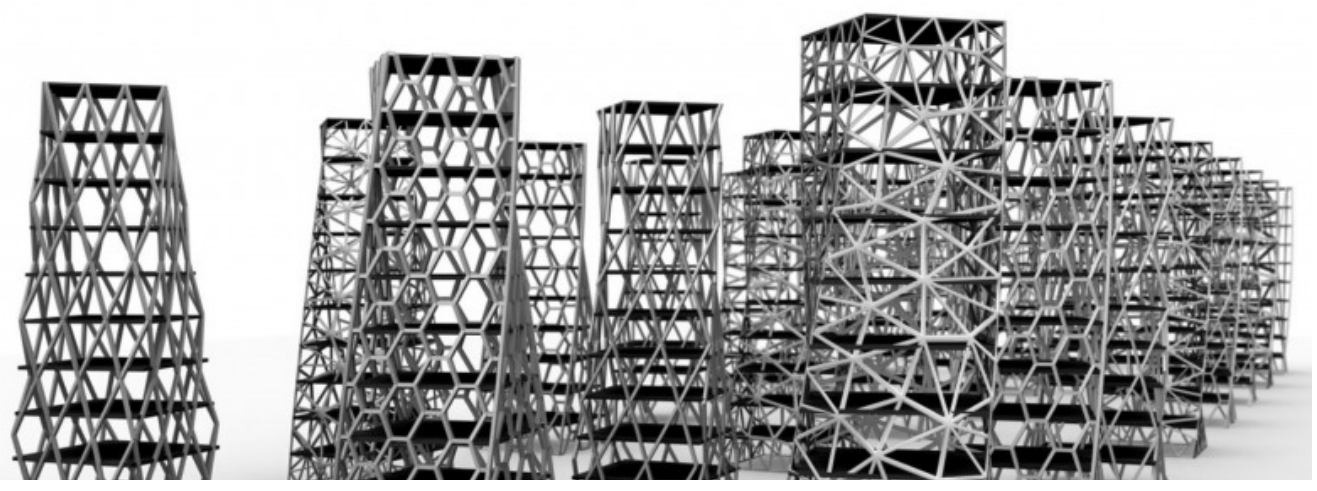

Figure 2: Generative modeling with Grasshopper. Creation: Architect Ernesto Bueno

Courtesy: LABI Laboratório de Ideias and Atelier UM + D

The main functions of open facade elements are: ventilation, lighting, thermal insulation and hide of indoor construction. Figures 3 and 4 present the projects consist of hollow elements of high geometric complexity, produced with geopolymer mortar. Figure 5 shows several types of architectural elements produced in geopolymer mortar used in the replica of Solomon's Temple (base and chapiter of columns, upper and lower roof cornices and crowning).

The specification of geopolymer material provides numerous advantages over other materials, which include: reproduction of elements in high definition and excellent surface finish from standard fiberglass molds; rapid and controllable curing, which allows increased productivity through reuse of molds; low shrinkage allowing the perfect fit between parts; high resistance to fire and heat; durability and significant reduction of greenhouse gas emissions in its production, which generate environmental benefits proportionately.
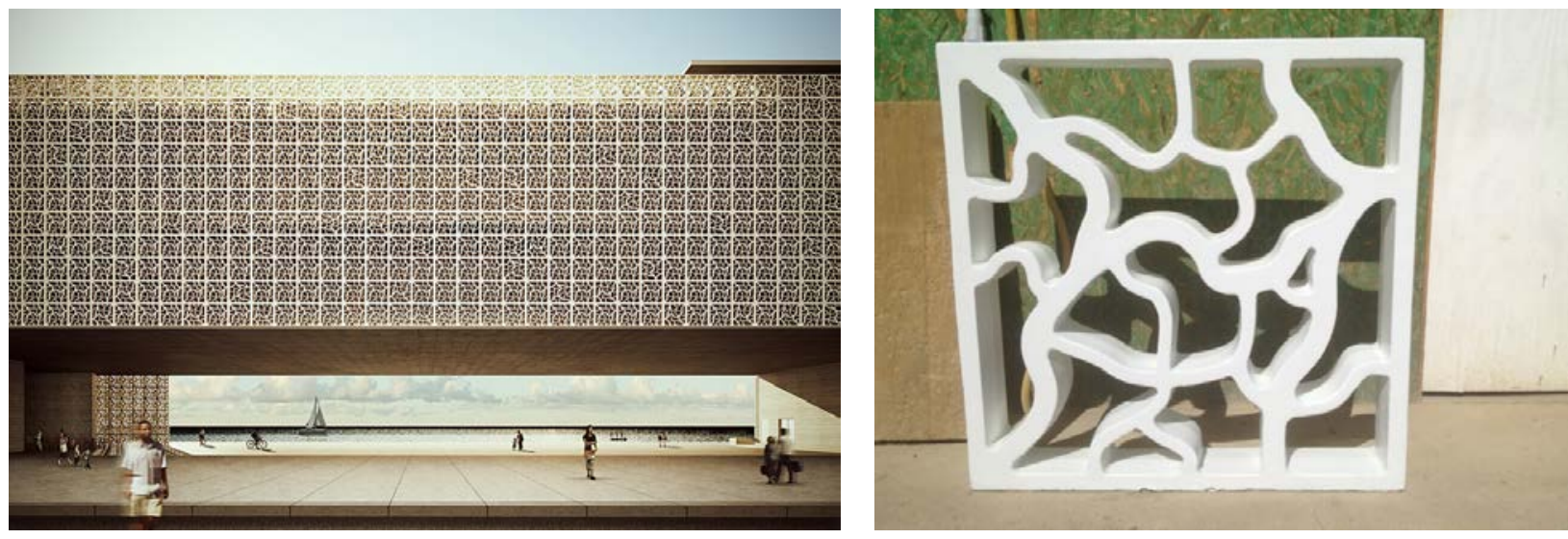

Figure 3: Cultural center Cais do Sertão Luiz Gonzaga in Recife. Project: Brazil Arquitetura Courtesy: Wincret Designer Concrete Products. 

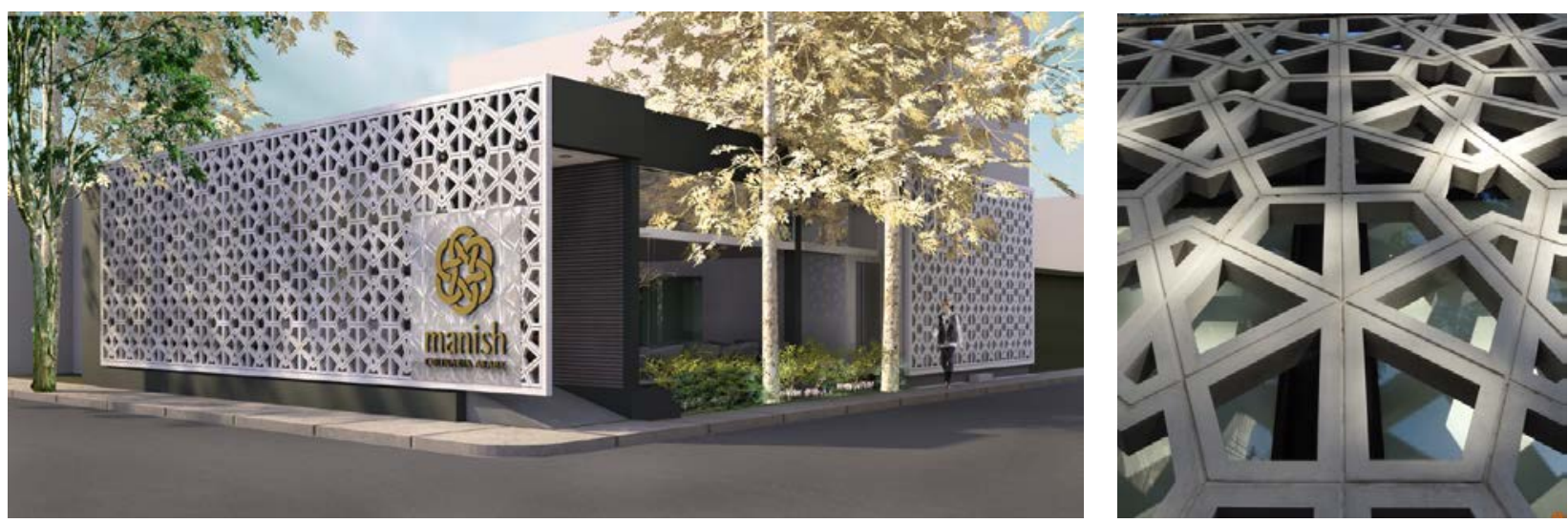

Figure 4: Arabic restaurant in São Paulo. Project: ODVO Architecture and Urbanism. Courtesy: Wincret Designer Concrete Products.
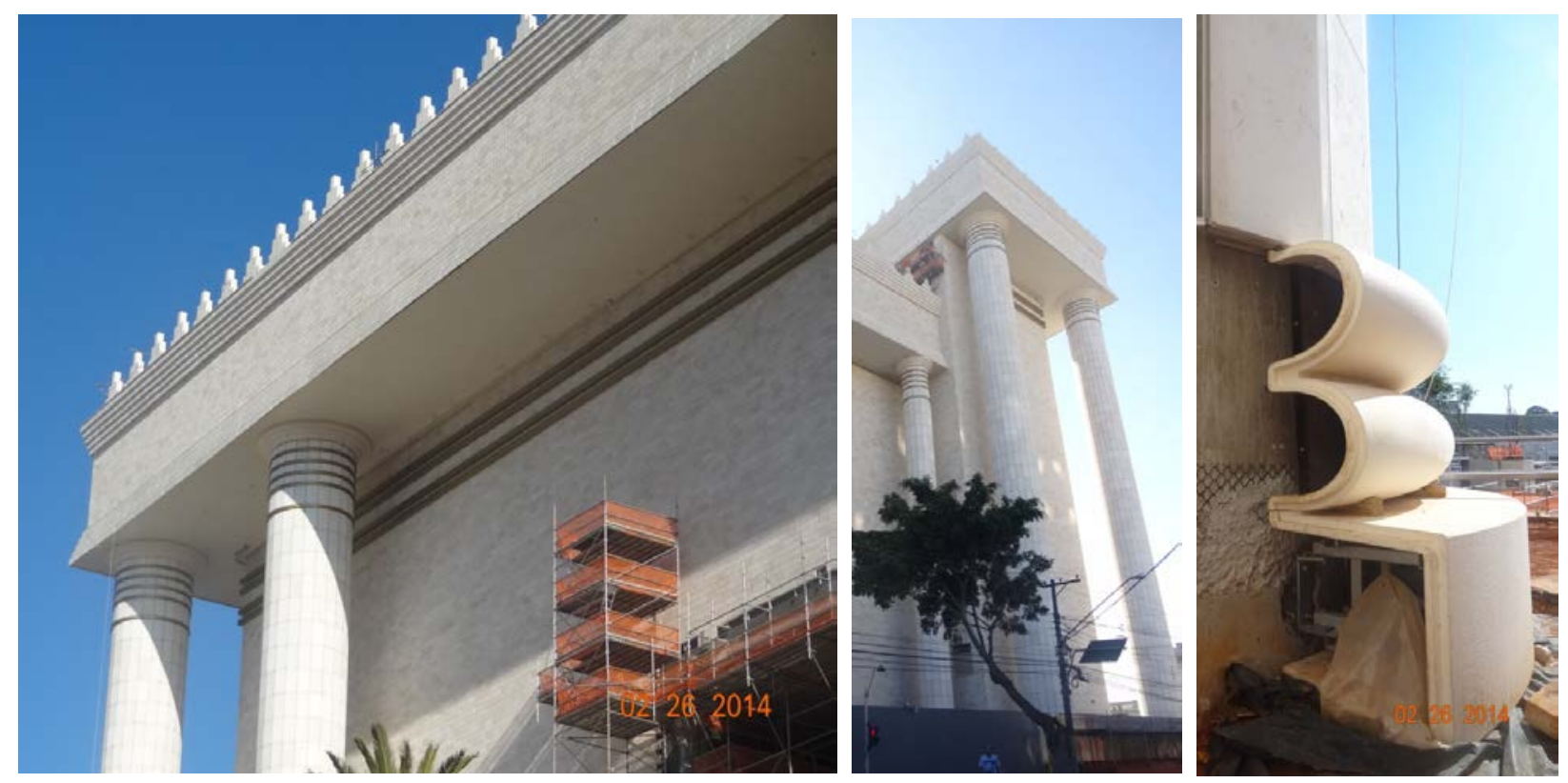

Figure 5: Solomon's Temple (São Paulo) Project: M Mazza Arquitetura.

Courtesy: Wincret Designer Concrete Products.

\section{Composition of geopolymer mortar}

The geopolymers are binder materials that can be obtained by alkaline activation of natural or industrial products, including dejects and solid waste containing aluminosilicate in an amorphous state. It should be noted that there is a wide diversity of materials that can be considered precursors geopolymeric that are still little explored or even unknown in terms of research [2].

The geopolymerization, a term created by Joseph Davidovits [3], is related to the alkaline activation at low temperatures and free handling. It is a reaction that integrates silicon and aluminum forming molecular structures comparable to natural rock features. In this process, occurfs concatenated reactions: dissolution, condensation and formation of three-dimensional interconnected network. The materials obtained by alkaline activation, in general, exhibit higher mechanical strength and durability than those obtained by hydraulic activation, as is the case with ordinary Portland cement.

The formulation presented in this study has metakaolin (calcined at $750^{\circ} \mathrm{C}$ ) as the precursor and silicate compound (potassium silicate with the addition of potassium hydroxide) as an activator. The molar composition ratios adopted aim to optimize the mechanical strength. It was considered the alkaline activator compound (silicate + hydroxide) because it has a larger and more complete reactivity compared to simple alkaline activator (silicate). The alkaline solution can be composed of sodium or potassium. Sodium is most effective in the dissolution of aluminosilicate contained in the 
metakaolin, however, it leads to a higher viscosity which implies a lower workability. According to Joseph Davidovits [3], the activating solutions potassium-based promote greater mechanical strength to the geopolymer and they are less aggressive at handling in relation to sodium-based solutions. The starting raw materials are: metakaolin, potassium silicate, potassium hydroxide, water and sand, with a ratio of dry binder and fine aggregate equal to two. The molar ratios used (Table 1) favor the formation of geopolymer POTASSIUM-(POLISIALATO SILOXO), whose atomic ratio between silicon and aluminum is equal to 2. Potassium silicate has a silica modulus of 3.26 and with the addition of potassium hydroxide this ratio drops to 1.65, increasing the reactivity of the solution without compromising the free handling of personal protective equipment.

Table 1: Molar ratio of geopolymer

\begin{tabular}{|c|c|c|c|}
\hline \multicolumn{2}{|c|}{ RAW MATERIALS } & OXIDE & MOLAR RATIO \\
\hline PRECURSOR & METAKAOLIN & $\mathrm{SiO}_{2}: \mathrm{Al}_{2} \mathrm{O}_{3}$ & 2 \\
\hline \multirow{5}{*}{ ACTIVATOR } & \multirow{2}{*}{$\begin{array}{l}\text { POTASSIUM } \\
\text { SILICATE }\end{array}$} & $\mathrm{SiO}_{2}: \mathrm{K}_{2} \mathrm{O}$ & 3.26 \\
\hline & & WATER & $50 \%$ \\
\hline & \multirow{3}{*}{$\begin{array}{l}\text { SILICATE + } \\
\text { POTASSIUM } \\
\text { HIDROXIDE } \\
\end{array}$} & $\mathrm{SiO}_{2}: \mathrm{K}_{2} \mathrm{O}$ & 1.65 \\
\hline & & $\mathrm{H}_{2} \mathrm{O}: \mathrm{K}_{2} \mathrm{O}$ & 11.3 \\
\hline & & WATER & $45 \%$ \\
\hline \multirow{4}{*}{\multicolumn{2}{|c|}{$\begin{array}{l}\text { GEOPOLYMER TYPE K-(PSS)* } \\
\text { Si:Al=2 } \\
\text { *POTASSIUM-(POLI-SIALATE SILOXO) }\end{array}$}} & $\mathrm{SiO}_{2}: \mathrm{Al}_{2} \mathrm{O}_{3}$ & 3.5 \\
\hline & & $\mathrm{K}_{2} \mathrm{O}: \mathrm{SiO}_{2}$ & 0.27 \\
\hline & & $\mathrm{K}_{2} \mathrm{O}: \mathrm{Al}_{2} \mathrm{O}_{3}$ & 0.94 \\
\hline & & $\mathrm{H}_{2} \mathrm{O}: \mathrm{Al}_{2} \mathrm{O}_{3}$ & 9.7 \\
\hline
\end{tabular}

To calculate the quantities of starting materials, in addition to the technical data of products manufactured, X-ray Fluorescence analysis was realized to quantify the oxides present in an amorphous state. The mix order, begins with the homogenization of metakaolin and sand (dry part) followed by the addition of the activator solution using a mechanical mixer. The activator solution is prepared 24 hours prior at room temperature to complete the release of the hydroxyls and increase the reactivity of the solution.

\section{Experimental program}

Two sets of experiments were performed to characterize the mechanical properties of geopolymer mortar required in the mathematical representation in finite element models. The first includes testing for obtaining elastic properties and stress limits of the material by means of standardized specimens. The second set involves a nonstandard pull-out and push-out tests of the metallic body and bending tests of geopolymer plates reinforced with carbon fiber fabrics.

Standard tests. The specimens were densified in vibrating table for expelling the gas phase, and demolded in 24 hours and cured, wrapped in PVC film, in a room temperature at $25^{\circ} \mathrm{C}$ and relative humidity at $60 \%$ until the date of the tests. The tests described below were carried out at 7 days of age and results are the average values obtained from three specimens.

Compressive strength. The compressive strength prescribed in Brazilian standard NBR 7215:1996 [4], were obtained from the molding of cylindrical specimens, three for each specified date, $50 \mathrm{~mm}$ diameter by $100 \mathrm{~mm}$ high. The ages are tested at 4 and 24 hours, 3, 7, 14, 21 and 28 days. It is observed from the analysis of Figure 6, a rapid growth of the compressive strength and points out that the seventh day is reached the approximate mean value $f_{\mathrm{c}}=60 \mathrm{MPa}$, which corresponds to $85 \%$ of the resistance obtained at 28 days. 


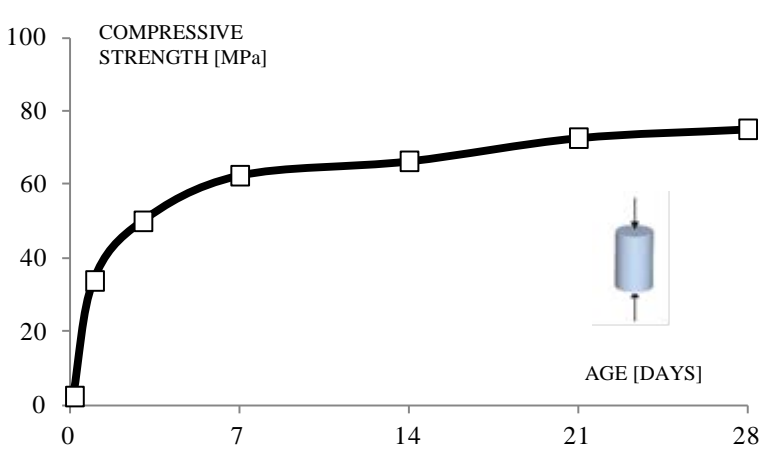

Figure 6: Evolution of the compressive strength of geopolymer mortar

Tensile strength in bending. The average breaking load of $P=3 \mathrm{kN}$ was obtained in the bending test at three points in prismatic specimens of dimensions $40 \mathrm{~mm}$ wide by $40 \mathrm{~mm}$ high and $160 \mathrm{~mm}$ in length (100 mm of span length). The specimens were prepared according to the procedure described above. The ASTM C 348 [5] specify that the flexural strength of specimens made of cement mortars, according to the dimensions established by testing, it is $f_{\mathrm{ct}, \mathrm{fl}}=0.0028 \cdot P=$ 8.4 MPa, where $P$ is the maximum load $[\mathrm{N}]$ and $f_{\mathrm{ct}, \mathrm{fl}}$ is a tensile strength in bending [MPa]. The average tensile strength $f_{\mathrm{ctm}}$ was obtained indirectly through the bending test. According to the standard CEB-FIP [6] can correlate these strengths by the expression:

$$
f_{c t m}=0.44 \cdot f_{c t, f l}=0.44 \cdot 8.4=3.7 \mathrm{MPa} .
$$

Modulus of elasticity. The standard BS EN 12390-13 [7] prescribes the method for obtaining the secant modulus of elasticity in compression for normal concrete. These guidelines enable the obtaining of two modules: the initial, measured on the first loading cycle, and the stabilized, measured after three loading cycles. Cylindrical test specimens of dimensions $50 \mathrm{~mm}$ diameter by $100 \mathrm{~mm}$ height were used, adapted for geopolymer mortar [4]. The calculation of axial deformation was taken based on the length corresponding to the half-height of the specimen in three positions lagged by 120 degrees. The loading cycles were composed of two phases: three preload cycles of intensity $f_{\mathrm{cm}} / 9$ followed by three loading cycles of intensity $f_{\mathrm{cm}} / 3$, where $f_{\mathrm{cm}}$ is an average compression strength previously calculated. The Figure 7 shows the loading cycles applied on specimens cylindrical, based on compression strength $f_{\mathrm{cm}}=60 \mathrm{MPa}$ which corresponds approximately to an axial load of $120 \mathrm{kN}$. In this figure are highlighted in which the stages of loading the modulus of elasticity were obtained. Although the difference between the values of the initial secant modulus and stabilized is indicative of the susceptibility of the material to the formation of stress-induced microcracks process, this study used only the secant modulus of elasticity stabilized.
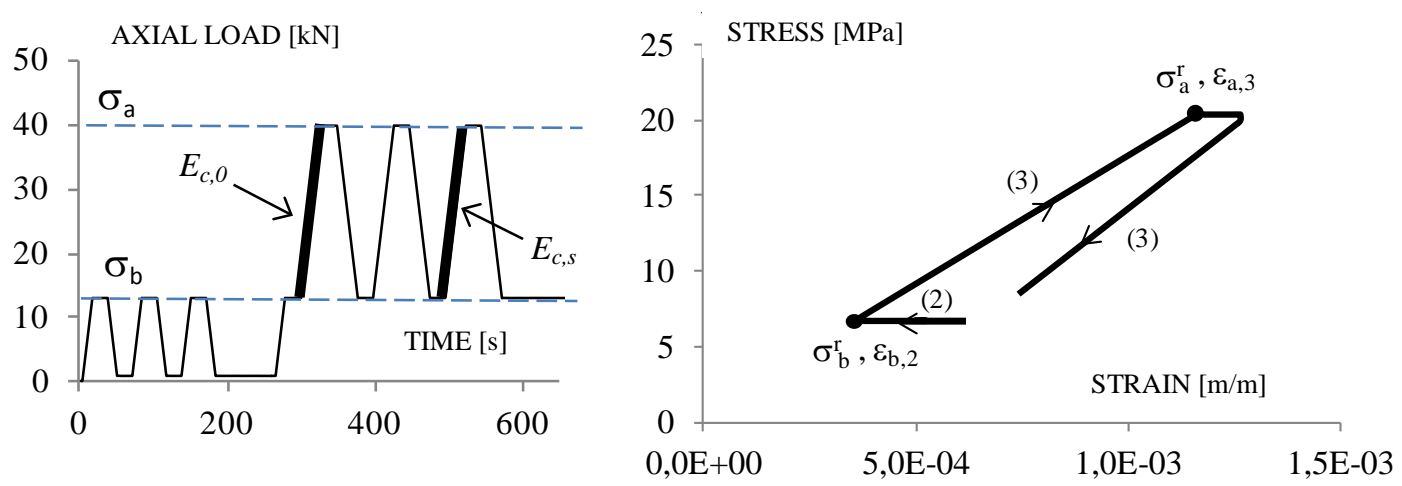

Figure 7: Loading cycles for testing the secant modulus of elasticity 
The secant modulus of elasticity $E_{\mathrm{c}, \mathrm{s}}$ (stabilized) is defined by [7];

$$
E_{\mathrm{c}, \mathrm{s}}=\frac{\Delta \sigma}{\Delta \varepsilon_{s}}=\frac{\sigma_{a}^{r}-\sigma_{b}^{r}}{\varepsilon_{a, 3}-\varepsilon_{b, 2}}=18074 \mathrm{MPa} \approx 18 \mathrm{GPa}
$$

being the points of interest are shown in the stress-strain diagram shown in Figure 7, corresponding to the average of the three readings.

Poisson's ratio. The Poisson's ratio was calculated according to the requirements of ASTM C 469:02[8]. The test was performed with the same samples used in modulus of elasticity test. The measurements of diametral deformations were taken in the half-height on three points lagged 120 degrees with stress corresponding to $40 \%$ of the compressive strength $f_{\mathrm{c}}=60 \mathrm{MPa}$, obtained after three loading cycles. The Poisson's ratio is defined by [8]:

$$
\mu=\frac{\varepsilon_{12}-\varepsilon_{11}}{\varepsilon_{2}-0,000100}=0,18
$$

where $\varepsilon_{12}$ is a diametral deformation in the semi-height of the specimen produced by the axial load $50 \mathrm{kN}$ (about $40 \%$ of the resistance to compression $f_{\mathrm{c}}=60 \mathrm{MPa}$ ), $\varepsilon_{11}$ is a diametral deformation in the semi-height of the specimen produced by the axial load that causes a longitudinal deformation of 100 microstrains and $\varepsilon_{2}$ is a longitudinal deformation with respect to half-height of the specimen produced by the axial load $48 \mathrm{kN}$. Although ASTM suggests that the initial deformation is taken to 50 microstrains, related to the cylindrical specimens of $150 \mathrm{~mm}$ diameter for $300 \mathrm{~mm}$ high, Poisson's ratio was calculated for 100 microstrains, because were used cylindrical specimens out of standard.

Fracture energy. The fracture energy was obtained according to the recommendations of RILEM FMC standard [9], which is applied specifically for concrete and mortars, through of threepoint bend test on notched beam. The test was performed with prismatic specimen of 40mm wide by $40 \mathrm{~mm}$ high by $160 \mathrm{~mm}$ long with $152 \mathrm{~mm}$ span and notch with a depth of half the height of the mid-span section. The area under the load versus displacement curve obtained in the test (Fig.8) represents a term of the energy expression of the fracture energy expressed by:

$$
G_{\mathrm{F}}=\left(W_{0}+m g \delta_{0}\right) / A_{\text {lig }}=83,63 \mathrm{~N} / \mathrm{m}
$$

where $m g$ is the weight of the sample plus the weight of the devices installed on the specimen, $\delta_{0}=0.80 \mathrm{~mm}$ is the final displacement obtained in testing and $A_{\text {lig }}$ is the area of the resistant section in the middle of the span.

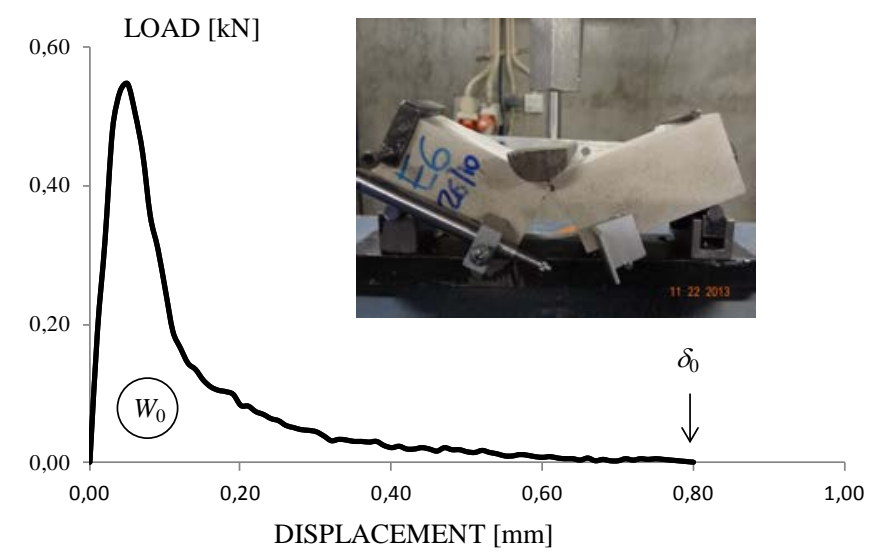


Figure 8: Load-displacement curve and fracture energy for bending test

Nonstandard tests. The specimens were prepared in the same way as standard test specimens.

Pull-out test. The pull-out test of a metallic body of the insert was performed with plate specimen of dimensions $100 \mathrm{~mm}$ by $100 \mathrm{~mm}$ and $22 \mathrm{~mm}$ of thickness. The metallic body was positioned at the geometric center of the sample and anchored at the depth of $18 \mathrm{~mm}$ from the top face. The sample was tested at a steel plate fixation, with central hole of $65 \mathrm{~mm}$ diameter, sufficiently rigid so as not to show bending stresses in the specimen, which can perturb the results of pull-out force. The displacement velocity adopted for the test was 30 micrometers per second. There was no dependence on the diameter of the hole of plate, which defines unconfined surface, with the angle formed by the pull-out cone (Fig. 10). Two configurations were tested: cylindrical and conical metallic body. The Figure 9 shows the load-displacement curve obtained from the two test configurations. It is observed that the ultimate pull-out forces for the two configurations are very close. For all tested samples values above $2.5 \mathrm{kN}$ were recorded. It is noted that the type of rupture observed for the sample with conical metallic body was brittle, whose value of the load was governed by the value of the tensile strength of geopolymer mortar. On the other hand, the cylindrical metallic body has frictional forces distributed along the lateral surface, and furthermore, may manifest chemical bonds in interface metallic body/geopolymer, favoring the increase of adhesion strength. Thus, it may explain the increased ductility of this configuration. The energy required to promote pull-out of the cylindrical metallic body is higher, about three times that of the conical configuration, despite the ultimate pull-out forces are equivalent. In this case, the highest safety was obtained to the cylindrical configuration. This statement also applies to cases of preventive maintenance that can detect faults of the anchoring system, for small displacements and material breakdown occurred in the metallic insert region (Fig. 10), preventing from serious accidents that may occur by loosening the plate. Evaluates the load-displacement curve (Fig. 9) it can be observed small accommodations of the metallic body, promoting rigid body motion, whose energy is restored by frictional forces distributed on the lateral surface of the metallic body to a force that toward to residual friction that precedes the pull-out strength limit. For practical purposes, the post-peak portion is discarded.

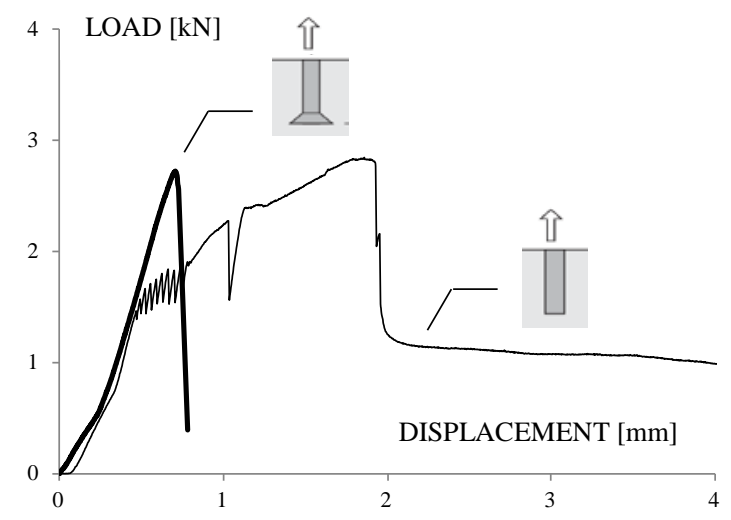

Figure 9: Load-displacement curve of the test of pull-out metallic body
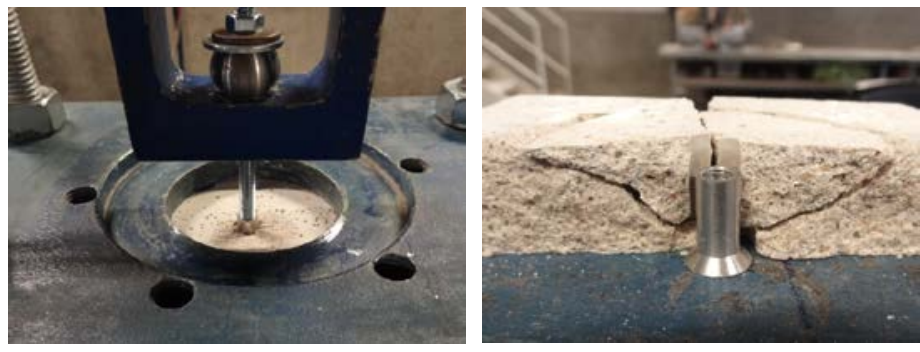

Figure 10: Test pullout body of internal thread (left) cylindrical configuration with slip (right) pullout test of conical insert 
Push-out test. The push-out test of metallic body was carried out analogously to pull-out test. In this case, the two configurations provide a post-peak reserve, because both have the frictional forces present along the lateral surface of the metallic body. For the two cases examined, the rupture type occurs by inverted cone and post-peak reserve observed is concerned to the frictional forces present in the surrounding surface of the remaining confined part. Comparatively, the portion of material segregated was higher for the conical configuration (Fig. 12), but the remaining portion was less confined. This effect could be interpreted that the energy required for punching the cylindrical metallic body is larger than the conical configuration, showing that the effect of friction is dominant in all cases analyzed.

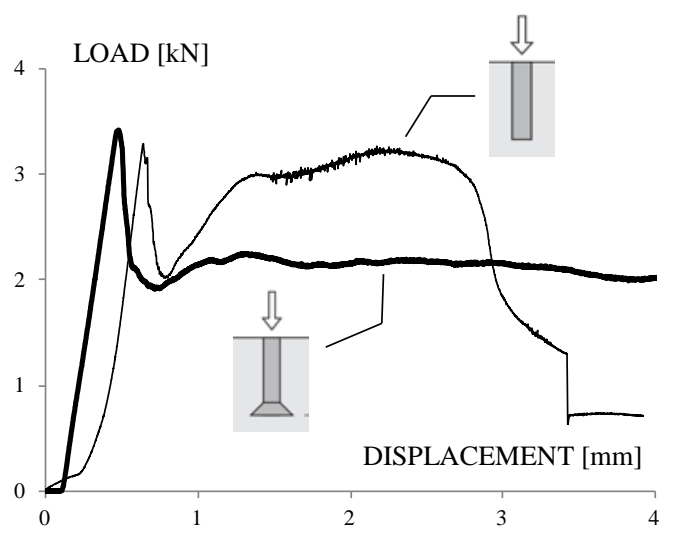

Figure 11: Load-displacement curve for push-out test of the metallic body

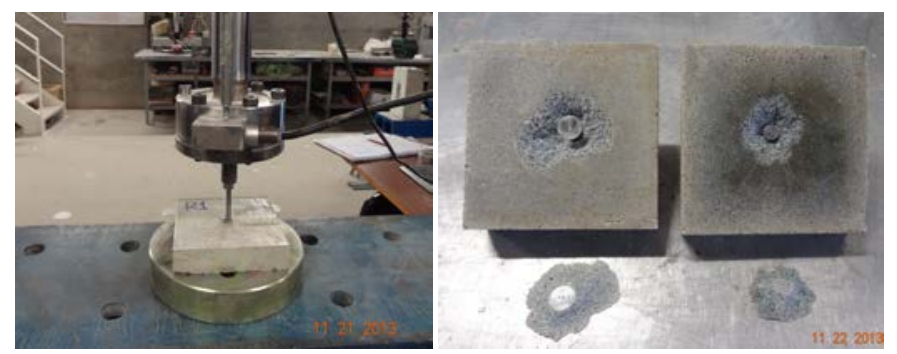

Figure 12: Pull-off test of metallic body (left) configuration the test (right) push-off inverted cone for the two configurations

Plate bending test. Plate bending tests were performed with a testing machine with displacement controlled coupled to a continuous mounting device from the edges of the plate with adjustable positioning to allow traction and compression punching tests (Fig. 13). Only the case of conical metallic body was tested. The application of load on the metallic insert was monotonically increasing, with displacement rate of $0.5 \mathrm{~mm} / \mathrm{min}$ with three preloading cycles imposed until the maximum force of $200 \mathrm{~N}$, to mitigate possible abrupt accommodation occurred the supports and internal devices. The geometric configuration of the plate is shown in Figure 14. For the case of traction punching test, the reinforced plate has a one layer of bidirectional carbon fiber mesh, $2 \mathrm{~mm}$ from the upper side (negative) in the form of orthogonal crossed strips (Fig. 15). For the case of compression punching test, the reinforced plate has one or two layers of bidirectional carbon fiber mesh, $2 \mathrm{~mm}$ from the bottom face (positive) covering the whole area of the plate (Fig.15).The test results of plate bending will be presented ahead.

\section{Numerical program}

The numerical program was developed in ATENA Computer Program for Nonlinear Finite Element Analysis of Reinforced Concrete Structures, version 5.02 [10]. Three types of nonlinearities are defined: physical (for the description of the constitutive model adopted for each material), geometric (for analysis problems limit) and contact (to simulate the effects of interface 
regions of discontinuity). Two types of analyzes were performed: analysis of parameters calibration (for adjusting the physical properties and stiffness of contact at the interface geopolymer mortar/metallic body) and limit analysis (to predict the behavior of the plate for two loading cases, until to exhaustion of its bearing capacity).
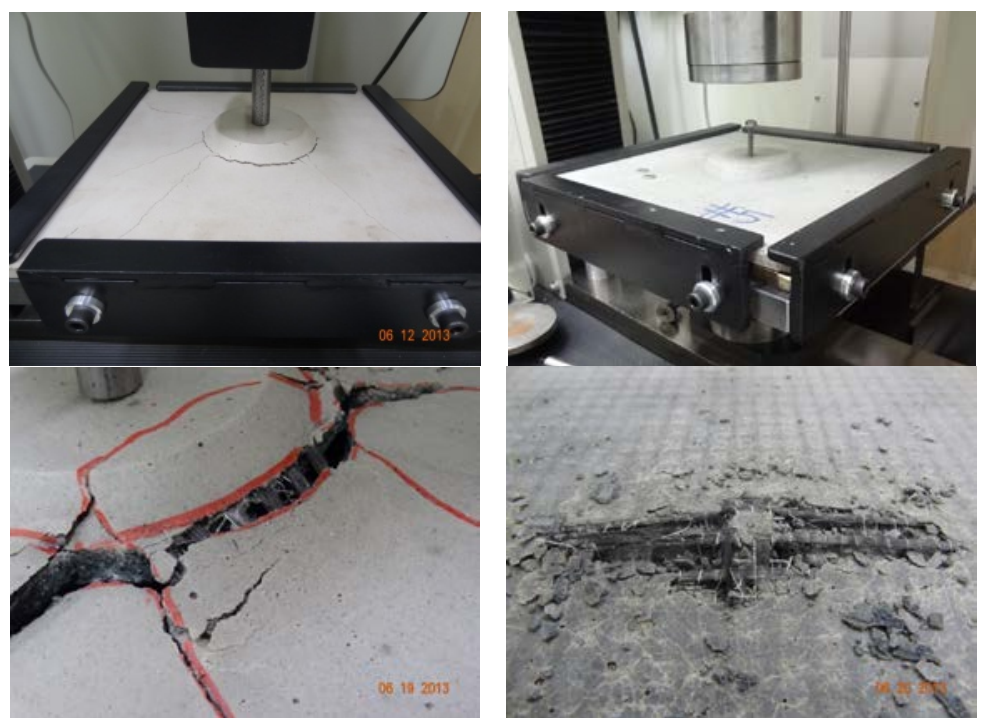

Figure 13: Bending test plate (left) traction punching and rupture mode (right) compression punching and rupture mode
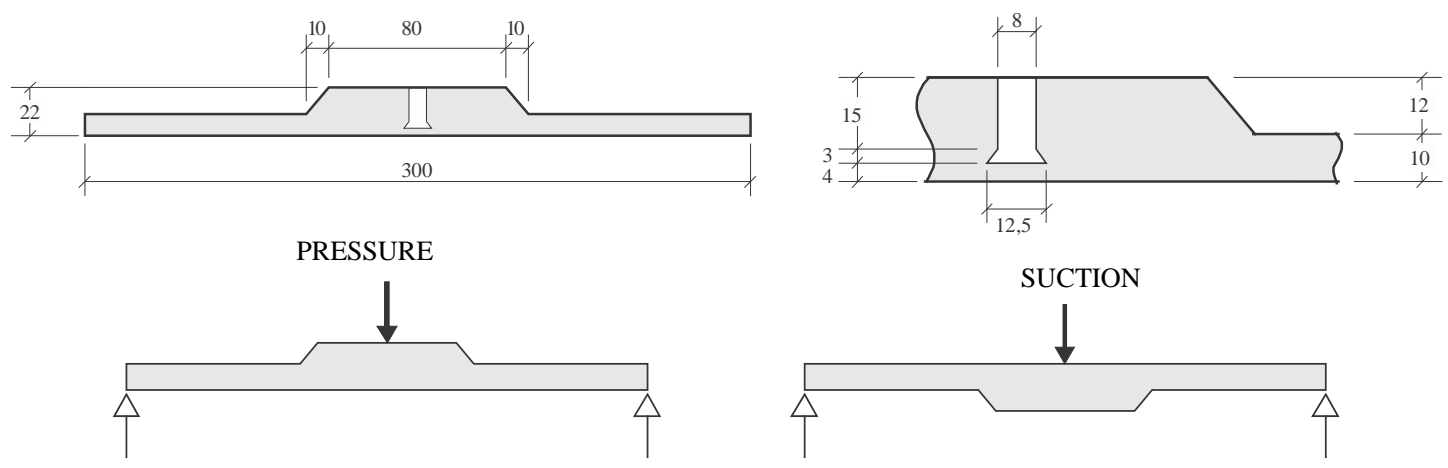

Figure 14: Geometrical characteristics of the plate and loading and boundary conditions
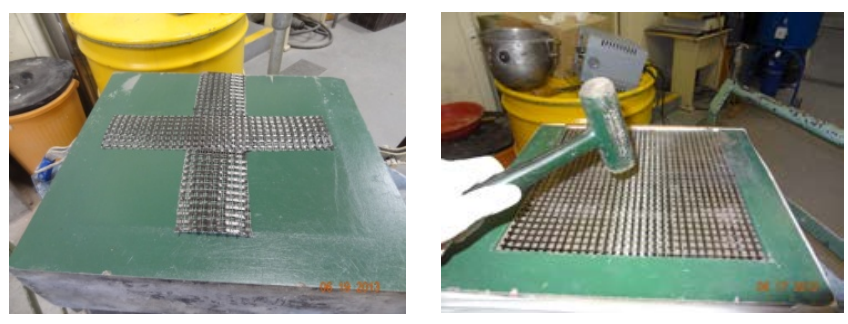

Figure 15: Layout of the bidirectional carbon fiber mesh (left) traction punching configuration (right) compression punching configuration

Constitutive models. The constitutive model adopted for the geopolymer mortar was described by the Menetrey-Willam failure criterion associated to the rule of cracking written in terms of fracture energy which is the governing physical parameter for the formation, propagation and opening cracks. For the carbon fiber was assumed perfect elastic-plastic behavior for tension-only. In case of occurrence of compressive stresses the element is disabled. For the metallic body, was assumed linear elastic behavior, whose stress-strain relationship is defined solely by the modulus of elasticity of steel. For interface geopolymer mortar/metallic body was used the Mohr -Coulomb Criterion delimiting the boundary between the laws of bond/slip to shear stress and bond/detachment to normal stresses. Figure 16 summarizes the behavior of materials of the model of finite elements and the properties obtained in the experimental program. 


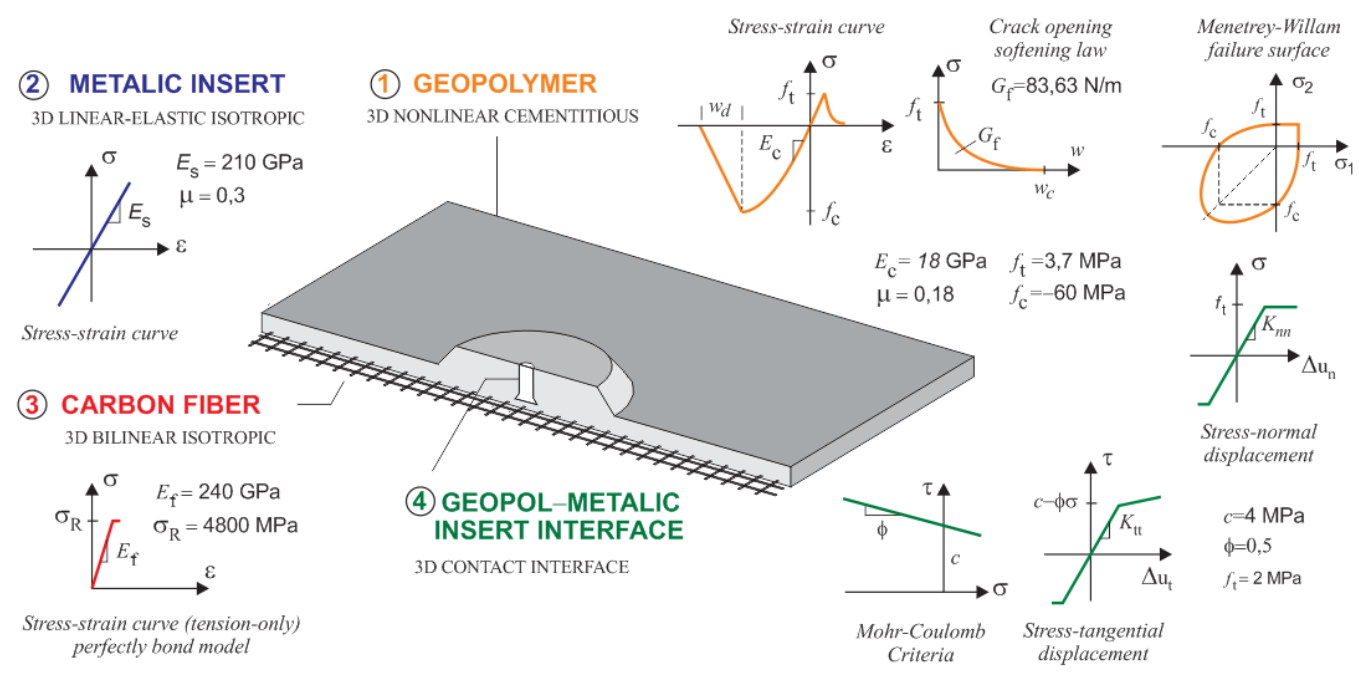

Figure 16: Definitions and characterization of the materials considered in the mathematical model

Analysis of parameters calibration. Two finite element models were developed to reproduce the pull-out and push-off tests performed. Based on peak-loads obtained in the tests were adjusted, by back analysis to partially confined model, the parameters related to the Mohr-Coulomb Criterion. The resulting values were cohesion $\mathrm{c}=4 \mathrm{MPa}$, friction coefficient $\phi=0.50$ and bond resistance $f^{\mathrm{T}}=2 \mathrm{MPa}$. It was also necessary contact stiffness in the interface, which relates shear stresses with tangential displacements and normal stresses with normal displacements, by means to linearelastic relationship on perfectly bond condition.

Limit analysis. Five finite element models were developed to predict the peak-load of the plate for two loading conditions and three reinforcement configurations. The limit analysis was carried out to exhaustion of the bearing capacity of the plate, and the simulated bending tests presented. The mechanical and physical properties obtained in the experimental program and the calibration model were used, presented in Figure 16. The Figure 17 shows the results obtained by the finite element model of the plate in compression punching condition with two layers of carbon fiber reinforcement next to the exhaustion of the bearing capacity of the plate. It is observed that the stresses in carbon fiber fabric reach the value of $1217 \mathrm{MPa}$, showing its efficiency this limit condition. Also noteworthy, distribution of cracks observed in the upper and lower faces that are consistent with the state of cracking observed in the experimental program (Fig. 13).
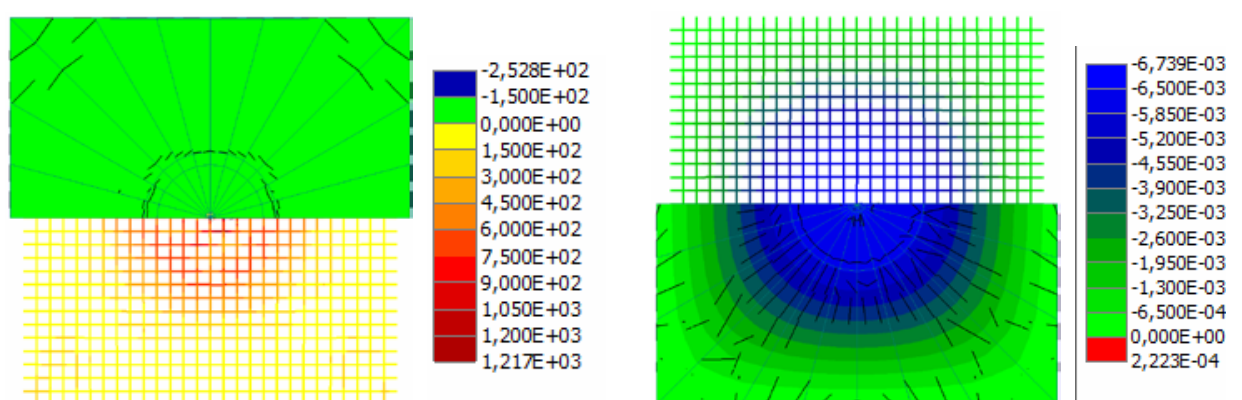

Figure 17: Plate under compression punching with two carbon fiber mesh and crack opening larger than $0.3 \mathrm{~mm}$ (left) axial stresses [MPa] in carbon fiber (right) vertical displacements [m] 


\section{Comparison of results}

Figures 18-22 show the results of numerical and experimental programs for the five analyzed cases.
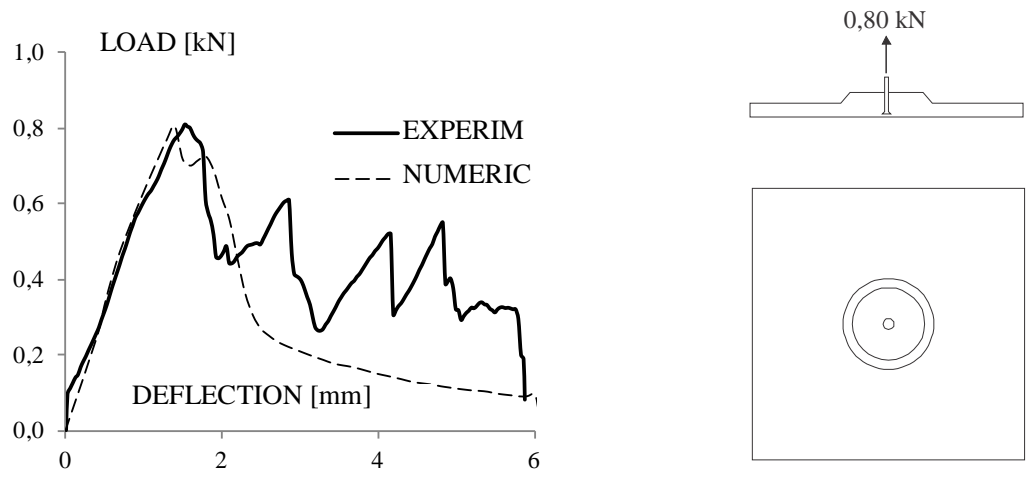

Figure 18: Load-deflection curve for traction punching test without carbon fiber reinforcement
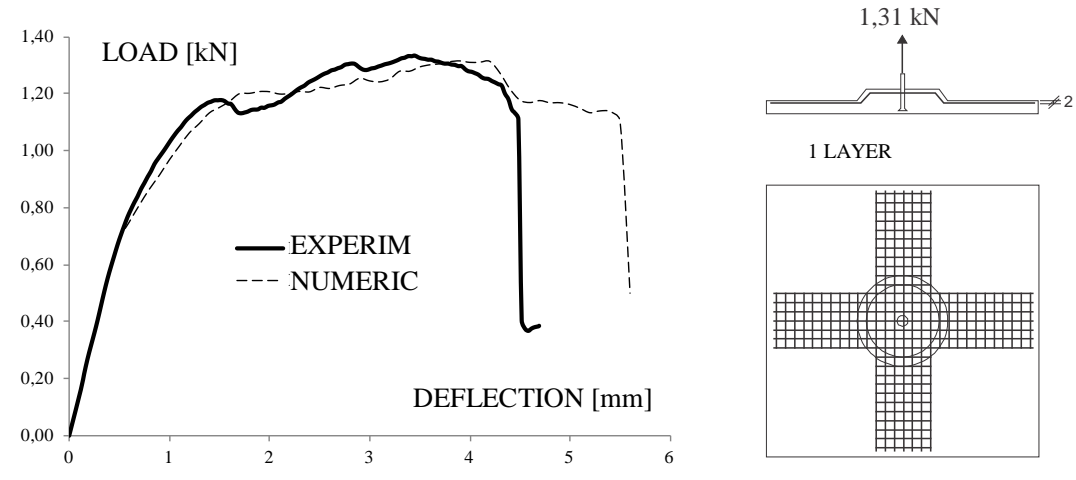

1 LAYER

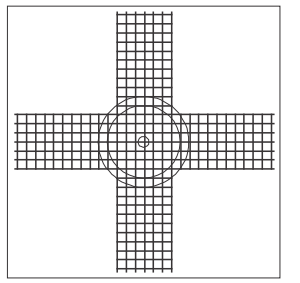

Figure 19: Load-deflection curve for traction punching test with one layer of carbon fiber reinforcement

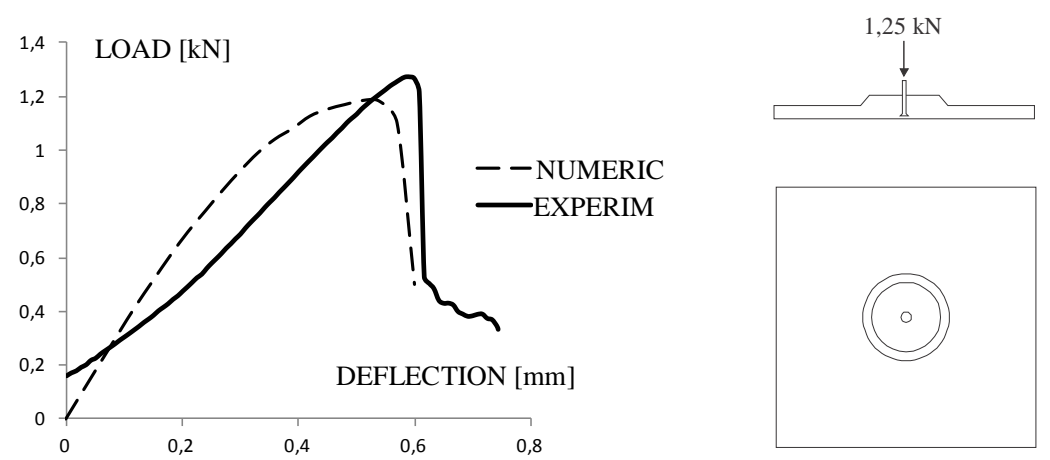

Figure 20: Load-deflection curve for compression punching test without carbon fiber reinforcement
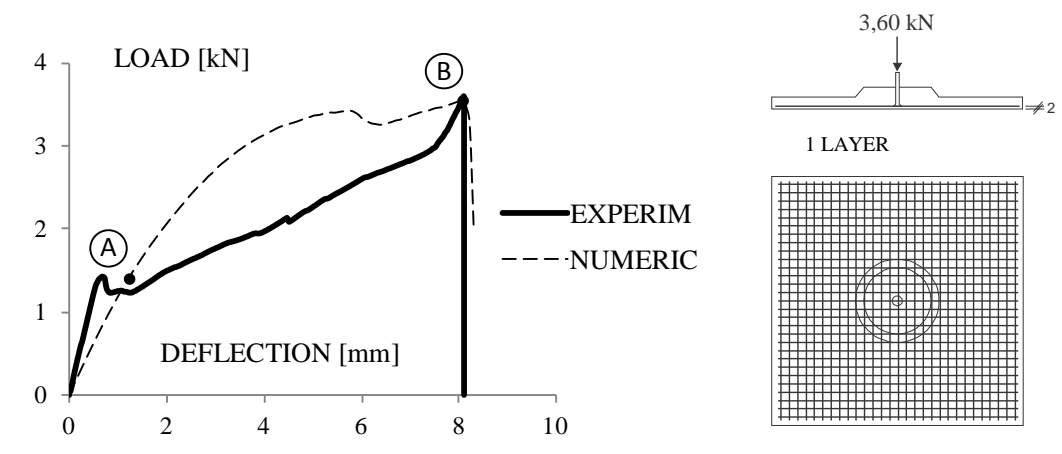

Figure 21: Load-deflection curve for compression punching test with one layer of carbon fiber reinforcement 


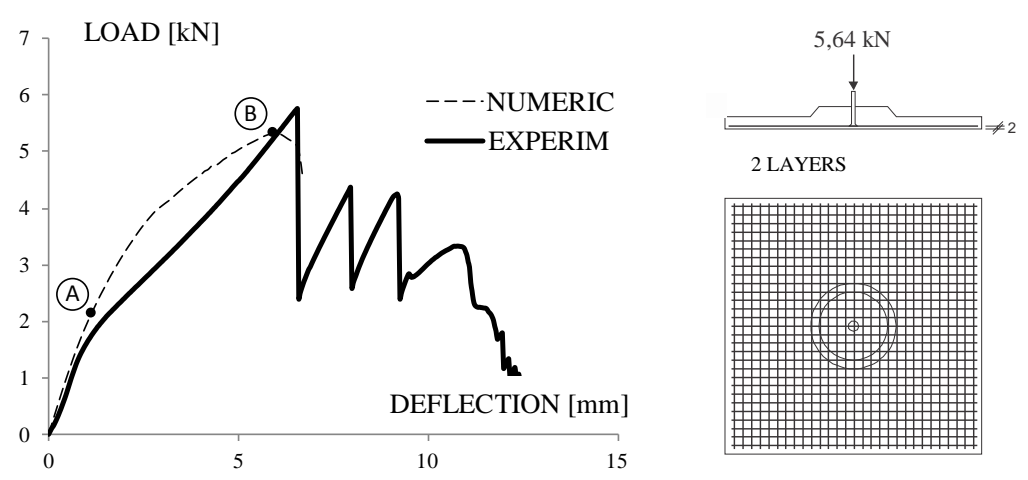

Figure 22: Load-deflection curve for compression punching test with two layers of carbon fiber reinforcement

Comparisons between numeric and experimental results show that the maximum loads differ by less than 10 percent. It makes no sense to adjust this value exactly as tests show variations of the order of $20 \%$ of this load. As the plate stiffness two situations occur. First, concerning the case of traction punching (Fig. 18 and Fig.19), the defined plate stiffness in a finite element model represent faithfully the behavior observed in the tests. The other, referring to the case of compression punching (Fig. 20, Fig. 21 and Fig. 22), the lack of adhesion between the results is influenced by the interaction between the plate bending and the efforts on the interface. It is observed that this effect increasing the bearing capacity. In this case, due to the coupling between normal and tangential stresses, it requires a new calibration which is more representative. Beyond this fact, it is emphasized that the presence of carbon fiber mesh can lead to discontinuities by the presence of incorporated air, which leads to a localized loss of stiffness and that was not considered in the finite element model. Other possible reasons to explain the lack of adhesion between the results are: loss of verticality of the metallic body, which in the case of compressive forces this geometric imperfection is more evident, and difficulty for the exact positioning of the mesh of carbon fiber in the in manufacturing process of the plate.

It makes no sense to describe the numerically critical post-crack opening behavior above $0.3 \mathrm{~mm}$, while not imply a risk to the safety of the plate (as, for example, diseases associated with the corrosion of reinforcing steel) because leads to an unpleasant aesthetic effect. Beyond this point, there is a relative displacement of the metallic body for loss of adhesion at the interface with the geopolymer plate. The recovery seen in post-critical peaks (Fig. 22) is derived from the frictional forces that are pronounced in the plate/metallic body interface. This behavior was not reproduced in a finite element model because there is no practical interest.

\section{Final remarks}

The use of geopolymer mortar promotes energy efficiency of constructions reflected in significant gains in the environmental field. The use of geopolymer mortar brings numerous advantages in the production of precast and exhibit excellent performance as protective materials against fire and high temperatures in buildings in fire conditions.

At present, the search for unique architectural concepts and the use of new materials emphasize the importance of experimental and numerical evaluations for the safety of the structures. The nonlinear mathematical models allow clearly describe the failure mechanisms of structural elements reinforced with composite systems with high-strength fibers. The use of these resources leads to decision-assertive decision on the use of reinforcement to increase the bearing capacity and ductility of structural elements.

Future investigations will focus on the effects caused by long-term behavior of geopolymer mortar for impact resistance and substantial temperature increase in fire in order to meet the criteria and minimum levels of performance demanded by today's standards. 


\section{Acknowledgements}

To Conselho Nacional de Desenvolvimento Científico e Tecnológico (CNPq) by granting a postdoctoral scholarship to the first author.

And to Wincret Designer Concrete Products Ltda. by the supply of raw materials and mold plate and the development of the composition of the geopolymer mortar.

And to Sika Brazil S/A for providing bidirectional carbon fiber mesh.

And last, but not least, to the Laboratório de Estruturas and Laboratório de Materiais de Construção do Departamento de Engenharia Civil da Universidade do Minho, the Laboratório de Materiais de Construção and Laboratório de Caracterização e Processamento de Materiais da Universidade Presbiteriana Mackenzie by the experimental campaign.

\section{References}

[1] TEDESCHI, Arturo. Parametric architecture with Grasshopper. Ed. Le Penseur, Brienza, 2010.

[2] TEIXEIRA PINTO, A. Sistemas ligantes obtidos por activação alcalina do metacaulino. Tese de Doutoramento. Universidade do Minho, 2004.

[3] DAVIDOVITS, J. Geopolymer: Chemistry and Applications. 3. ed. Geopolymer Institute. Saint Quentin, 2009.

[4] NBR 7215:1996 - Cimento Portland: determinação da resistência à compressão, método de ensaio. Associação Brasileira de Normas Técnicas. Rio de Janeiro, 1996. 8 p.

[5] ASTM C 348:02. Standard test method for flexural strength of hydraulic-cement mortars. American Society for Testing and Materials. West Conshohocken, August, 2002.

[6] CEB-FIP Model Code 1990. Comité Euro-Internacional do Betão, Boletim de Informação n. 195/196, março, 1990.

[7] BS EN 12390-13. Testing hardened concrete - Part 13: determination of secant modulus of elasticity in compression. British Standards Institution. London, November, 2013.

[8] ASTM C 469:02. Standard test method for static modulus of elasticity and Poisson's ratio of concrete in compression. American Society for Testing and Materials. West Conshohocken, August, 2002.

[9] RILEM TC50-FMC Determination of the fracture energy of mortar and concrete by means of three-point bend tests on notched beams. Materials and structures,v.18, n.106. London, JulyAugust, 1985.

[10] CERVENKA, V., CERVENKA, J. ATENA Theory: Program documentation. ATENA release 5.02. Cervenka Consulting. Prague, 2013. 